\title{
Influence of Tear Size on the Load Bearing Capacity of the Supraspinatus Tendon'
}

\section{Influencia del tamaño de la falla en la capacidad de carga del tendón supraespinoso ${ }^{2}$}

\author{
Alejandro Celemin ${ }^{3}$ \\ Rodrigo Vargas-Ariza ${ }^{4}$ \\ Juan C. Briceño ${ }^{5}$ \\ Juan C. González-Gómez ${ }^{6}$ \\ Daniel R. Suárez ${ }^{7}$
}

doi:10.11144/Javeriana.IYU18-2.its|

How to cite this article:

CELEMÍN A.; VARGAS-ARIZA R.; BRICEÑO, J. C.; GONZÁLEZ-GÓMEZ, J. C., and SUÁREZ, D. R. Influence of Tear Size on the Load Bearing Capacity of the Supraspinatus Tendon. Ingeniería y Universidad. 2014, vol. 18, no. 2, pp. 253-269. http://dx.doi. org/10.11144/Javeriana.IYU18-2.itsI

\footnotetext{
' Reception date: March $31^{\text {st }}, 2014$. Acceptance date: July $31^{\text {st }}, 2014$. This article is derived from the research project $U n$ modelo de elementos finitos simple: análisis de esfuerzos mecánicos en el tendón supraespinoso, developed by the Grupo de Ingeniería Biomédica de la Universidad de los Andes, el grupo Ortosantafe de la Fundación Santa Fe de Bogotá y el Departamento de Ingeniería Industrial de la Pontificia Universidad Javeriana, Bogotá, Colombia.

${ }^{2}$ Fecha de recepción: 31 de marzo de 2014. Fecha de aceptación: 31 de julio de 2014. Este artículo se deriva de un proyecto de investigación denominado Un modelo de elementos finitos simple: análisis de esfuerzos mecánicos en el tendón supraespinoso, desarrollado por el Grupo de Ingeniería Biomédica de la Universidad de los Andes, el grupo Ortosantafe de la Fundación Santa Fe de Bogotá y el Departamento de Ingeniería Industrial de la Pontificia Universidad Javeriana, Bogotá, Colombia.

${ }^{3}$ Ingeniero Mecánico, Universidad de los Andes, Bogotá, Colombia. Magíster en Ingeniería Mecánica, Universidad de los Andes. E-mail: a-celemi@uniandes.edu.co

${ }^{4}$ Médico cirujano, Universidad de los Andes, Bogotá, Colombia. E-mail: rodrigo.vargas.ariza@gmail.com

${ }^{5}$ Ingeniero mecánico, Universidad de los Andes, Bogotá, Colombia. Magíster en Ingeniería Biomédica, University of Texas at Austin, Estados Unidos. PhD, University of Texas at Austin. Profesor titular, Universidad de los Andes. ibriceno@uniandes.edu.co ${ }^{6}$ Médico cirujano, Pontificia Universidad Javeriana, Bogotá, Colombia. Magíster en Epidemiología Clínica, Pontificia Universidad Javeriana. Especialista en Ortopedia y Traumatología, Pontificia Universidad Javeriana. Educación Ortopédica en el Estudio del Hombro, University of Texas Health Science Center At San Antonio, Estados Unidos. Director del Servicio de Ortopedia, Fundación Santa Fe de Bogotá, Colombia. juangonz@uniandes.edu.co

${ }^{7}$ Ingeniero mecánico, Universidad de los Andes, Bogotá, Colombia. Magíster en Ingeniería Mecánica, Universidad de los Andes. Magíster en Ingeniería Biomédica, Delft University of Technology, Países Bajos. PhD, Delft University of Technology. Profesor asociado, Pontificia Universidad Javeriana. Correo electrónico: d-suarez@javeriana.edu.co
} 


\section{Abstract}

Supraspinatus tendon tearing is one of the most common injuries of the rotator cuff. This study aims to evaluate the effect of a full-thickness tear on the load bearing capacity of the supraspinatus tendon and to estimate the tear size at which the tendon cannot withstand physiological load. This study introduces a single value parameter, Strength Index (SI), which was estimated from a numerical model of the tendon with an increasing tear size. Critical Tear Size (CTS), defined as the tear size at which the tendon is unable to withstand maximal physiological load, was also estimated. SI and CTS were estimated for eight tear sizes and seven ultimate stresses to account for tear progression and patient variability, respectively. The $S I$ of the modeled tendon decreased with larger tear sizes. The effect of tendon ultimate stress on failure force decreased as the tear size increased. The CTS for the modeled tendon was estimated to be between 6 and $19 \mathrm{~mm}$, assuming an ultimate stress ranging from 1.6 to $12.6 \mathrm{MPa}$. The potential clinical applicability of CTS is limited to new techniques that allow for accurate estimation of the tissue ultimate stress.

\section{Keywords}

rotator cuff failure; supraspinatus tear; load bearing capacity

\section{Resumen}

La ruptura del tendón supraespinoso es una de las lesiones más comunes del manguito rotador. El objetivo de este estudio es evaluar el efecto de una ruptura del tendón en su capacidad de carga y estimar el tamaño de la ruptura a la cual el tendón no puede soportar carga en el rango fisiológico. Este estudio presenta un único índice que indica la capacidad de carga del tendón, Strength Index (SI), el cual se calcula usando un modelo computacional del tendón. También se calculó el tamaño crítico de la ruptura (CTS), definido como el tamaño de la ruptura a la cual el tendón no puede soportar una carga máxima. SI y CTS fueron estimados para 8 rupturas de tamaño creciente y 7 diferentes esfuerzos últimos para incluir variabilidad por crecimiento de la ruptura y del paciente, respectivamente. El SI de tendón disminuyó con el aumento del tamaño de la ruptura. El CTS para el tendón modelado fue estimado entre 6 y $19 \mathrm{~mm}$, asumiendo un esfuerzo último en un rango fisiológico entre 1,6 y 12,6 MPa. La posible aplicación clínica del índice CTS es limitada al surgimiento de nuevas técnicas que permitan la estimación in vivo acertada del esfuerzo último del tejido.

\section{Palabras clave}

falla del manguito rotador; ruptura del supraespinoso; capacidad de carga 


\section{Introduction}

A rotator cuff tear is a common cause of pain and disability among adults. Non-operative management of a rotator cuff tear is usually successful, although its outcome strongly depends upon a number of factors, including age, injury size, and functional demand of the shoulder (Blaine and Bigliani, 2005). Unfortunately, some tears progress during non-surgical management, resulting in treatment that is more difficult (Andarawis-Puri et al., 2009). Surgical management of rotator cuff syndrome yields good to excellent results in both function and pain relief (Blaine and Bigliani, 2005). In general, surgical management is only indicated for rotator cuff injuries with pain, reduced range of motion and high risk of progression; however, it is unknown which injuries are likely to propagate and which are not (Andarawis-Puri et al., 2009).

Clinical evidence indicates that the most common rotator cuff tears initiate as partial-thickness tears in the osteotendinous junction of the supraspinatus tendon (Andarawis-Puri et al., 2009; Carr and Harvie, 2005; Itoi et al., 1995; Sano et al., 1997). In its early stages, a partial-thickness tear propagates from the articular surface to the bursal surface of the tendon as it progresses to a fullthickness tear. The tear then propagates to the anterior and posterior edges of the insertion and in its final stages, to the subscapularis or infraspinatus tendons (Andarawis-Puri et al., 2009; Carr and Harvie, 2005; Itoi et al., 1995; Sano et al., 1997). Though geometrical and dimensional classifications of rotator cuff tears have been given (Burkhart, 2004; Davidson and Burkhart, 2010; Sallay et al., 2007), these categories do not provide criteria for surgical intervention.

In the absence of objective criteria for the surgical treatment of rotator cuff tears, a deeper understanding of rotator cuff mechanical behavior and failure mechanisms is required. This information would assist surgeons in diagnosis and surgical planning for rotator cuff injuries by indicating whether tear progression is imminent and whether surgery is needed.

A tear generates a discontinuity that concentrates stresses and reduces the tendon load-bearing capacity. To quantify how a tear affects the load bearing 
capacity, three aspects must be taken into account: rotator cuff and tear geometries, mechanical behavior of the tissue, and forces acting on the tissue. Previous literature considered these aspects in computational models of the supraspinatus insertion to evaluate its mechanical environment (Sano et al., 2007; Seki et al., 2008; Wakabayashi et al., 2003). Many of those studies simplified the tendon to a 2D geometry, and few have considered a 3D model (Seki et al., 2008; Inoue et al., 2012). Only two studies have considered either partial thickness tears (Sano et al., 2006) or suture of complete tears (Sano et al., 2007). Most studies oversimplify tendon mechanical behavior, modeling the tissue as a linear, isotropic material, and few studies have considered its non-linear behavior (Inoue et al., 2012). Tear initiation and partial thickness tears have also been studied in-vitro (Reilly et al., 2003a and 2003b; Yang et al., 2009). These studies estimated the mechanical environment of a healthy supraspinatus tendon and the initiation and progression of partial tears. No study has evaluated the change of the load bearing capacity of this tendon in the presence of full-thickness tears.

This study aims to evaluate the effect of a full thickness tear on the load bearing capacity of the supraspinatus tendon. To this end, this study proposes the use of a single value parameter, Strength Index $(S I)$, which is a function of the failure force of the tendon with and without a tear. Failure forces are estimated through a finite element model of the tendon with an increasing full-thickness tear. Tendon mechanical behavior is modeled as non-linear and transversely isotropic. The $S I$ is hypothesized to give insight into (a) whether a tendon with a tear is able to withstand maximal physiological tensile force and (b) the largest tear size, or the Critical Tear Size (CTS), at which the tendon can no longer support maximal physiological force.

\section{Materials and Methods}

A 2D finite element model of the supraspinatus tendon was implemented and used to estimate (a) the physiological range of ultimate strain corresponding to the previously reported ultimate stress of the supraspinatus tendon and (b) the force needed to produce a tear or enlarge an existing one $\left(F_{\text {fail,bealthy }}\right.$ and $F_{\text {fail,tear }}$, respectively), see Figure 1A. The $S I$ was defined in terms of the forces $F_{\text {fail, bealthy }}$ and $F_{\text {fail,tear }}$ and provided an index of the load bearing capacity of the tendon.

The relationships between the SI and tear size were plotted to study how load bearing capacity changes in the presence of increasingly larger tears. As the relationship between the $S I$ and tear size depends on tendon properties, a range of physiological ultimate stresses was considered. Additionally, the CTS 
was determined for seven ultimate stresses within the physiological range. The CTS was assumed to be reached when $F_{\text {fail,tear }}$ was equal to the maximum physiological force for the supraspinatus tendon $\left(F_{\text {physio }}\right)$. Finally, the relationship between the CTS and ultimate stress was plotted to investigate the influence of patient-to-patient variability on the results, see Figure $1 \mathrm{~B}$.

Figure 1. (a) Methodology used to estimate the forces needed to enlarge a tear.

(b) Estimation of the relationships between the Strength Index (SI) and Critical Tear Size (CTS) with ultimate stress and tear size

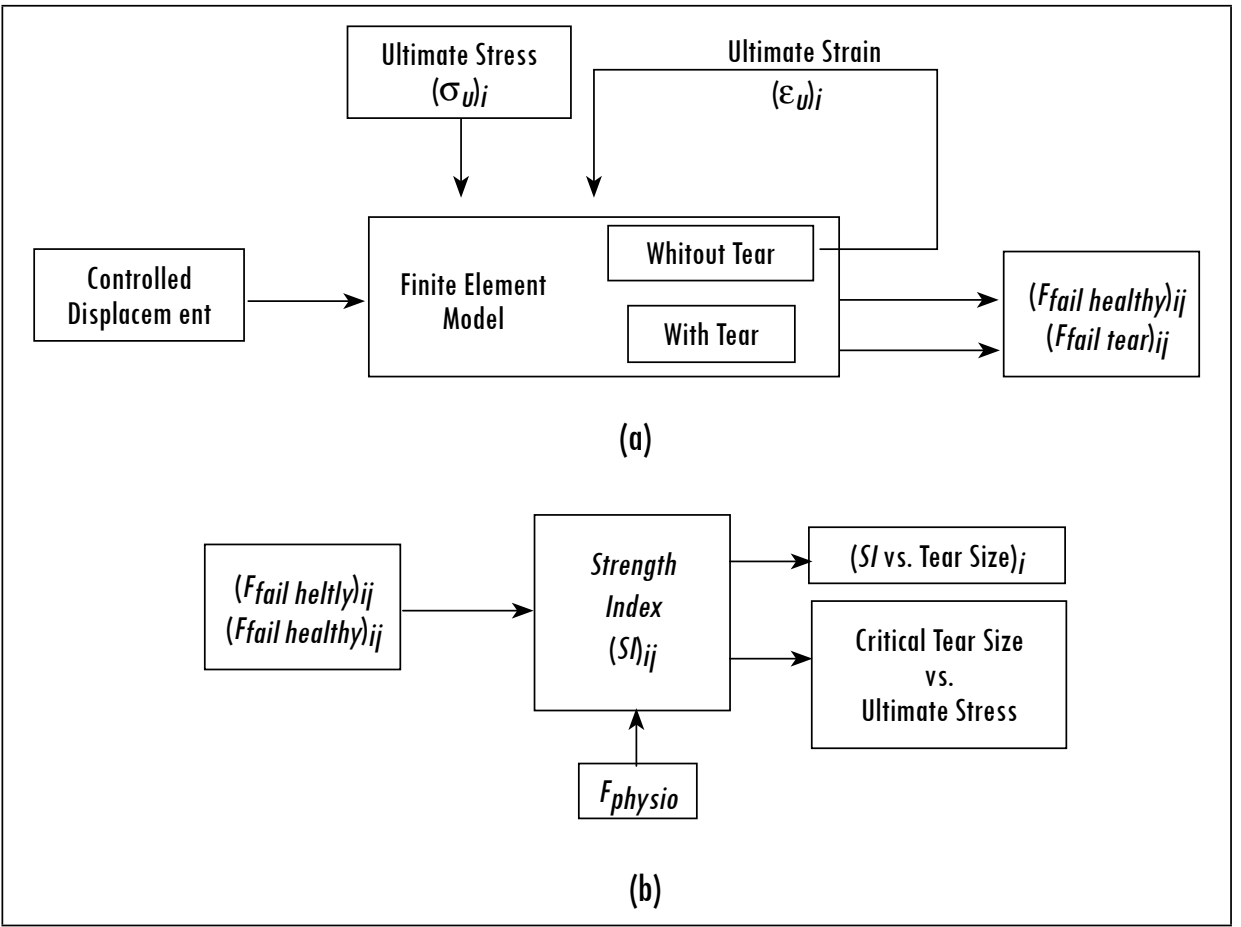

Source: authors' own presentation

\subsection{Strength Index (SI)}

The load bearing capacity of the supraspinatus tendon was quantified by the $S I$ using the ratio between $F_{\text {fail,tear }}$, as shown in Figure 2, and $F_{\text {fail,bealthy }}$ :

$$
S I=\frac{F_{\text {fail,tear }}}{F_{\text {fail,healthy }}}
$$


$F_{\text {fail,tear }}$ and $F_{\text {fail, bealthy }}$ were calculated using the finite element model presented in the next section. The $S I$ ranges from 1 in healthy tendon to 0 in a tendon with a tear size equal to the anterior-to-posterior width of the insertion. When $F_{\text {fail,tear }}$ equals $F_{p h s s i o}$, the CTS is achieved and the tendon cannot longer support physiological loading. A schematic of the relationship between the SI and CTS is shown in Figure 3. If $F_{\text {fail,tear }}$ is greater than $F_{\text {phssio }}$, the tendon is within its safety region where the tear has not reached the CTS and the tendon can withstand physiological loading. In contrast, if $F_{\text {fail,tear }}$ is smaller than $F_{p h y s i o}$, the tendon is within its risk region where the tear size is greater than the CTS. In this study, $F_{p h y s i o}$ of the supraspinatus muscle was set to $117 \mathrm{~N}$ (Hughes and An, 1996).

Figure 2. Failure of the tear edge fiber bundle at tendon ultimate strain $\left(\varepsilon_{u t}\right)$. The $2 \mathrm{D}$ finite element model of the healthy supraspinatus tendon was implemented to estimate the corresponding ultimate strain for the previously reported ultimate stress (range) of the supraspinatus tendon

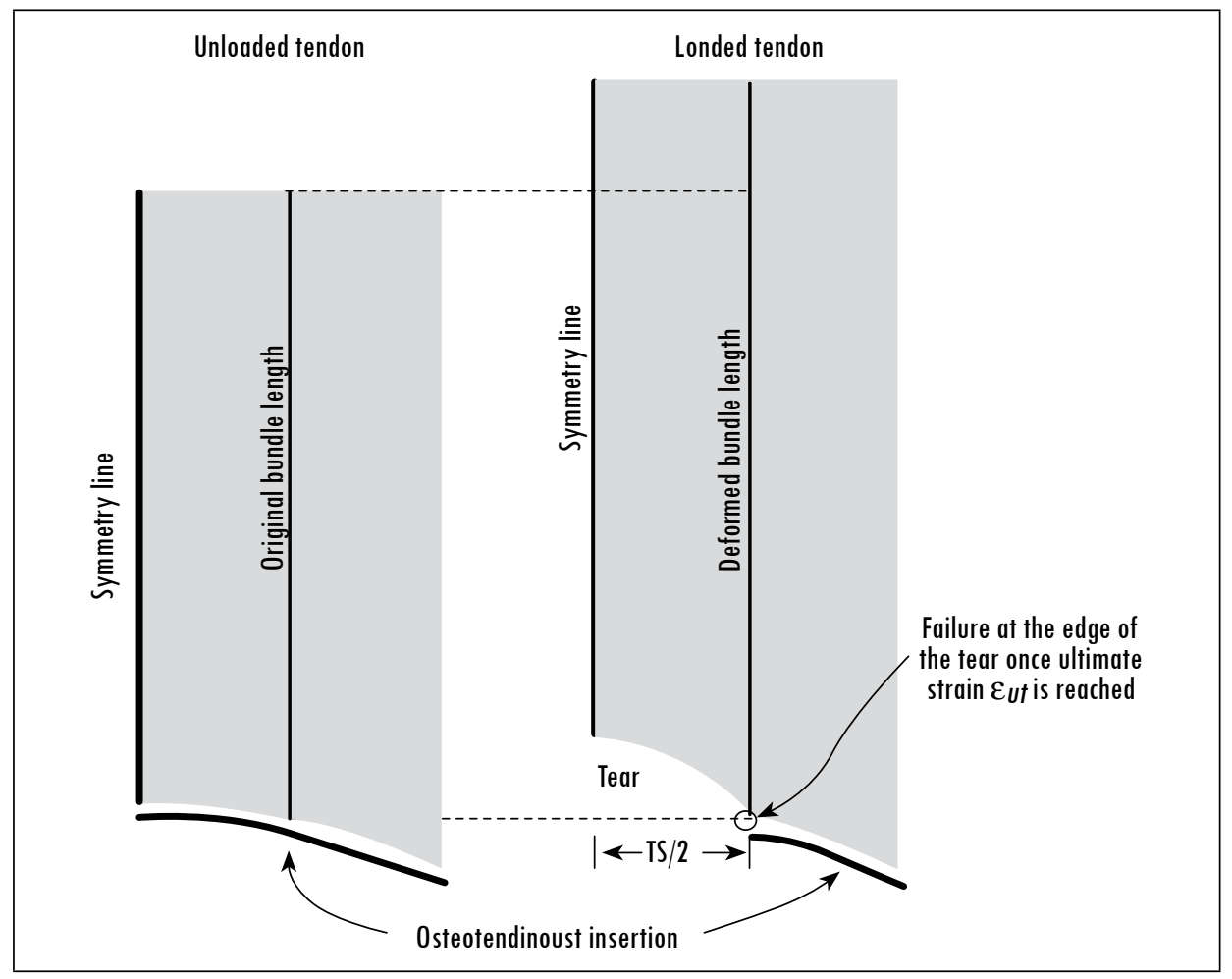

TS: tear size

Source: authors' own presentation 
Figure 3. Schematic of $S /$ behavior as function of the tear size for a given ultimate stress

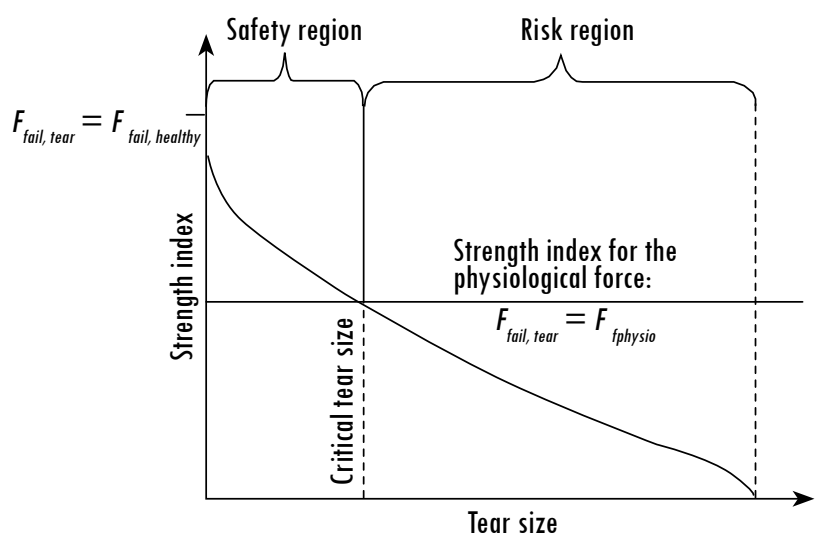

Source: authors' own presentation

\subsection{A Finite Element Model of the Supraspinatus Tendon}

A 2D finite element model of the supraspinatus tendon was implemented assuming a plane-stress approximation and solved in Comsol Multiphysics 4.2 (Comsol, Stockholm, Sweden). The tendon dimensions and material properties were measured or estimated from a cadaver tendon after approval of a local ethics committee. The tendon thickness was set to $5 \mathrm{~mm}$, and other dimensions are shown in Figure 4. The model consisted of 5,772 non-linear, quadrilateral elements with an average size of $0.2 \mathrm{~mm}$.

Figure 4. Simplified geometry of the supraspinatus tendon

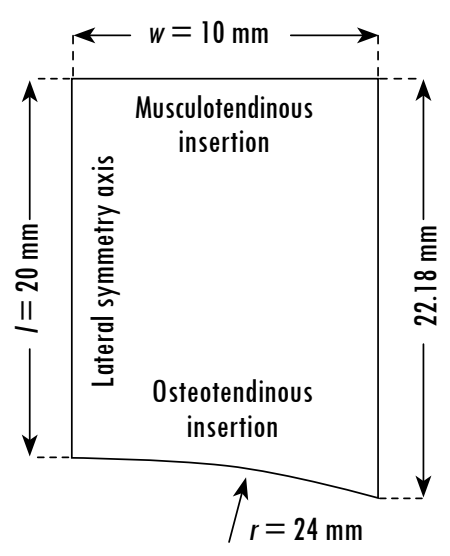

Source: authors' own presentation 
The osteotendinous insertion was modeled as a fixed boundary condition on the distal edge of the tendon. The tear size, or the anterior-to-posterior width of the tear, was controlled by releasing the corresponding nodes at the insertion. It was assumed that the tear starts from the middle of its osteotendinous insertion (Sano et al., 1997). Lateral symmetry was enforced by partially restraining the nodes along the left-hand boundary of the model, see Figure 4 . The model considered only tensile loading using a uniform displacement condition applied to the proximal edge of the tendon. The model was solved for eight different tear sizes, ranging from $0 \mathrm{~mm}$ (healthy tendon) to $19.6 \mathrm{~mm}$ wide.

\subsection{Constitutive Model of the Supraspinatus Tendon}

Four major assumptions regarding the mechanical behavior of the supraspinatus tendon and its properties were made in this study: nearly incompressible behavior, strain-rate insensitivity, homogeneity, and transverse isotropy. The tendon was assumed to be nearly incompressible because water content represents approximately 55\% of its total weight (Natali et al., 2005). Tensile tests have shown that tendons are relatively strain-rate insensitive within a physiological strain-rate range (Natali et al., 2005); therefore, viscous and dynamic effects were not considered in the model. The tendon was modeled as a transversely isotropic material with collagen fibers aligned in the longitudinal (loading) direction (Weiss et al., 1996; Natali et al., 2005).

For hyperelastic materials, including tendon, the stress-strain relation is defined by the Clausius-Duhem inequality (Holzapfel, 2000; Natali et al., 2005) as follows:

$$
S=2 \frac{\partial W(C)}{\partial C}
$$

where $\mathrm{C}$ and $\mathrm{S}$ are the second Piola-Kirchhoff stress tensor and the Cauchy-Green strain tensor, respectively, and $W$ is the free energy, or strain energy, function.

The strain energy function for nearly incompressible materials can be decoupled into its volumetric $(U)$ and deviatoric $(\tilde{W})$ components. Similarly, the deviatoric component of anisotropic materials can be decoupled into its isotropic $\left(\widetilde{W}_{m}\right)$ and transversely isotropic $\left(W_{f}\right)$ components (Natali et al., 2003). Therefore, the general form of the strain energy function for a tendon has the following form:

$$
W=U+\widetilde{W_{m}}+W_{f}
$$


The volumetric component of the strain energy function has the following form:

$$
U=\frac{K_{v}}{2}(J-1)^{2}
$$

where $K_{v}$ is the bulk modulus of the tendon, and $J$ is the volume ratio defined as the square root of the determinant of the right Cauchy-Green tensor (Ogden, 1997). The tendon bulk modulus was assumed to be $2 \mathrm{GPa}$ due to its water content (Natali et al., 2005).

The isotropic component of the deviatoric strain energy can be expanded into two parameters (Yeoh, 1993):

$$
\widetilde{W_{m}}=C_{10}\left(\tilde{I}_{1}-3\right)+C_{20}\left(\tilde{I}_{1}-3\right)^{2}
$$

where $\tilde{I}_{1}$ is the first modified invariant of the right Cauchy-Green tensor, and $C_{10}$ and $C_{20}$ are model parameters. Finally, the transversely isotropic component of the strain energy function has the following form:

$$
W_{f}=\frac{C_{3}}{\eta}\left(\exp \left(n\left(I_{4}-1\right)\right)-\eta\left(I_{4}-1\right)-1\right)
$$

where $C_{3}$ and $\eta$ are model parameters (Natali et al. 2003), and $I_{4}$ is the fourth invariant of the right Cauchy-Green tensor, which is given by the following:

$$
I_{4}=\mathrm{a}_{0} \mathrm{Ca}_{0}
$$

where $\mathrm{a}_{0}$ is a unit vector parallel to the collagen fiber direction (Holzapfel, 2000; Natali et al., 2005; Ogden, 1997).

This constitutive model included the mechanical contribution of collagen fibers and the tendon matrix, thereby incorporating the assumption of transverse isotropy. As a result, analytical expressions were derived to relate stress and stretch for both the longitudinal and transverse directions of the tendon. These expressions were implemented in the $2 \mathrm{D}$ finite element model of the supraspinatus tendon.

\subsection{Experimental Estimation of the Model Parameters}

A biaxial mechanical test of a supraspinatus tendon was performed to obtain the model parameters $C_{10}, C_{20}, C_{3}$, and $\eta$. The tendon, tested in a previous study (Celemin et al., 2012), was dissected using a standard surgical procedure from a cadaver after IEB approval (Comité de Ética de Investigaciones de la Universidad de los Andes, 
Acta 0722006). The subject was a male, $35 \mathrm{y} / \mathrm{o}$, without visible trauma or degeneration in shoulder tissues. The tissue extraction was done $12 \mathrm{~h}$ or less after decease and they were kept below $-4{ }^{\circ} \mathrm{C}$ in a local tissue bank (Fundación Cosme y Damián, Colombia) for a period not longer than $72 \mathrm{~h}$. The dimensions of the sample were measured before testing. The sample was attached to clamps by means of sutures and submerged in a $7 \%$ saline bath at $37{ }^{\circ} \mathrm{C}$ during preconditioning and testing. The preferential collagen fiber direction was aligned to one of the machine loading axes. The test was performed using a biaxial tensile testing machine (Bose SBP LMI Bench and a 2D Digital Video Extensometer, Farmingham MA, US).

The model parameters were estimated by fitting the experimental stressstretch data to an analytical stress-stretch expression using a built-in non-linear least-squares algorithm in MATLAB R2010a (MathWorks, Natik MA, US). The estimated parameters and a comparison between the predicted behavior of the tendon and the experimental data are shown in Table 1 and Figure 5, respectively.

Table 1. Estimated parameters for a human supraspinatus tendon

\begin{tabular}{|c|c|c|c|c|c|}
\hline Sample & $C_{10}$ & $C_{20}$ & $C_{3}$ & $\eta$ & $\kappa_{v}$ \\
\hline Tendon & $20,01 \mathrm{kPa}$ & $159,70 \mathrm{kPa}$ & $1,51 \mathrm{kPa}$ & 12,42 & $2 \mathrm{Gpa}$ \\
\hline
\end{tabular}

Source: authors' own presentation

\subsection{Failure Analysis}

In this study, failure refers to loosening of collagen fibers from the great tuberosity of the humeral head. Failure was assumed to occur when local fiber strain reached the ultimate strain of the tendon. This particular failure has been named as crescent-shaped or transverse tear and is the most common type of tear of the rotator cuff (Davidson y Burkhart 2010, Burkhart 2004, Sallay et al. 2007).

Previous experimental data report the ultimate stress of the supraspinatus tendon along the collagen fiber direction to be from 1.6 MPa to 12.6 MPa (Itoi et al., 1995; Sano et al., 1997). Seven different values within this range were considered in this study to include patient-to-patient variability. The corresponding ultimate strain $\left(\varepsilon_{u t}\right)$ for each ultimate stress was calculated in the finite element model of a tendon without a tear by measuring the relative displacement between two points along the same collagen fiber bundle. The failure criteria were set as the maximum fiber strain in the tendon when the displacement of the proximal margin of the tendon produced an average tensile stress equal to each considered ultimate stress. Because the tear was expected to grow along 
its insertion, the bundle of interest was located at the edge of the tear as shown in Figure 2. The ultimate stresses and strains are shown in Table 2.

Figure 5. Experimental stress-stretch data and the best fit for the tested tendon

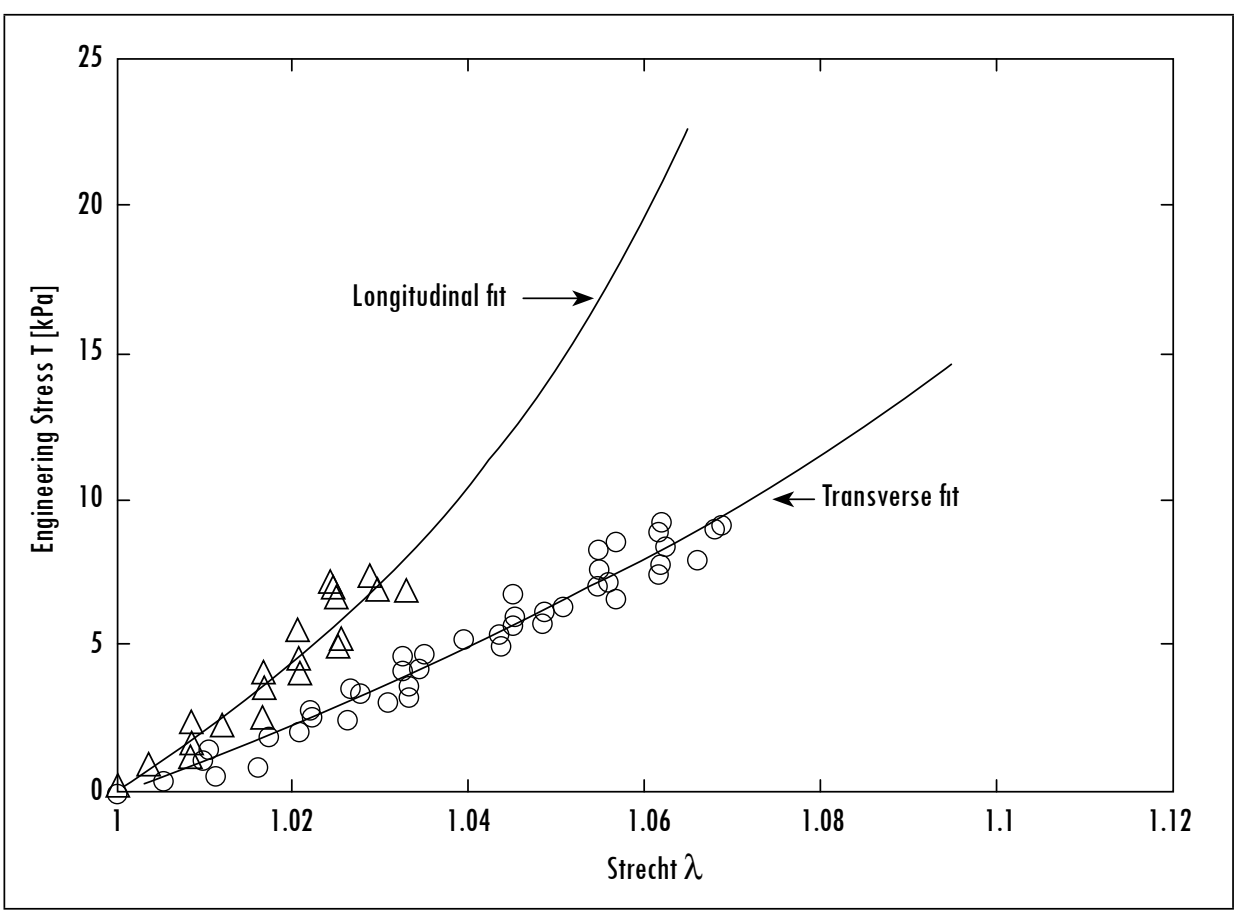

Source: authors' own presentation

Table 2 Corresponding ultimate strain $[\mathrm{mm} / \mathrm{mm}]$ for seven different ultimate stresses

\begin{tabular}{|c|c|c|c|c|c|c|c|}
\hline Ultimate stress [MPa] & 1.6 & 2.6 & 4.6 & 6.6 & 8.6 & 10.6 & 12.6 \\
\hline Ultimate strain [mm/mm] & 0.219 & 0.235 & 0.253 & 0.265 & 0.273 & 0.279 & 0.285 \\
\hline
\end{tabular}

Source: authors' own presentation

\section{Results}

The finite element model of the supraspinatus tendon provided three major results: The failure forces of a tendon with or without a tear; the $S I$, to evaluate the load bearing capacity of the tendon; and the CTS at which the tendon was no longer able to support a physiological force. As expected, $F_{\text {fail,tear }}$ was proportional to the ultimate stress of the tendon and inversely proportional to the tear size, as shown in Figure 6. 
The SI of the supraspinatus tendon was calculated for different tear sizes and ultimate stresses. The $S I$ was also inversely proportional to tear size. Curves of the $S I$ versus the tear size for the minimal and maximal considered ultimate stresses (1.6 MPa and 12.6 MPa) are shown in Figure 7. The CTS was calculated for each ultimate stress, as shown in Figure 8. The CTS was calculated to range from 6 to $19 \mathrm{~mm}$ for an ultimate stress ranging from 1.6 $\mathrm{MPa}$ to $12.6 \mathrm{MPa}$.

Figure 6. Failure force for different tear sizes and tendon ultimate stresses

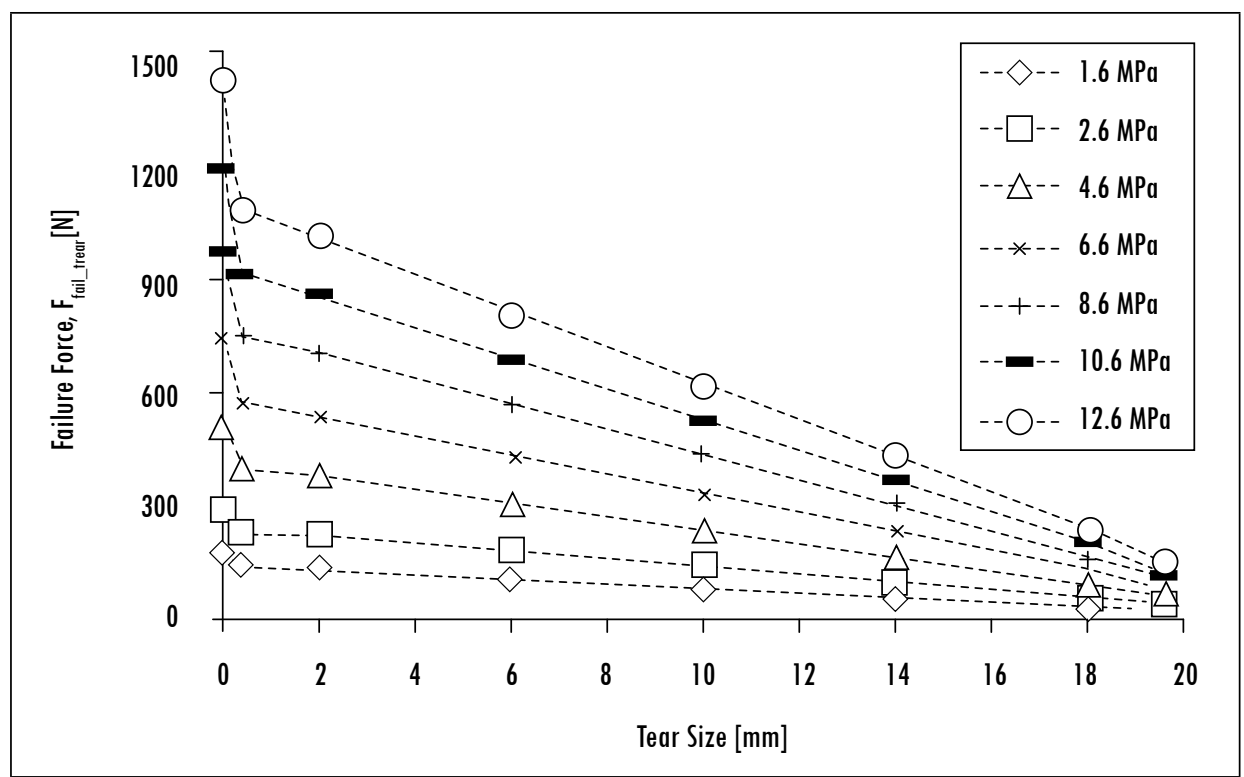

Source: authors' own presentation

\section{Discussion and Conclusion}

Previous numerical studies elucidated the stress state of the supraspinatus tendon under several scenarios. The first 2D models reported high stress near the tendon insertion (Wakabayashi et al., 2003) and around an initial tear (Sano et al., 2006). Seki et al. (2008) implemented a 3D model of the supraspinatus, however, the analysis was limited to one arm position $\left(0^{\circ}\right.$ abduction) and a very limited load (10 $\mathrm{N}$ on the proximal end of the tendon). Other models have predicted a higher shoulder load with a degenerated supraspinatus and arm abduction close to $90^{\circ}$ (Terrier et al., 2007). Inoue et al. (2012) used a non-linear $3 \mathrm{D}$ finite element model and found the highest stresses at $90^{\circ}$ abduction and 
a high risk of tear near the tendon insertion, which is the situation considered in the present study.

Figure 7. Strength Index (SI) for the tested tendon assuming an ultimate stress of $1.6 \mathrm{MPa}$ (Up) and $12.6 \mathrm{MPa}$ (Down) and an increasing tear size between 0 and $19.6 \mathrm{~mm}$
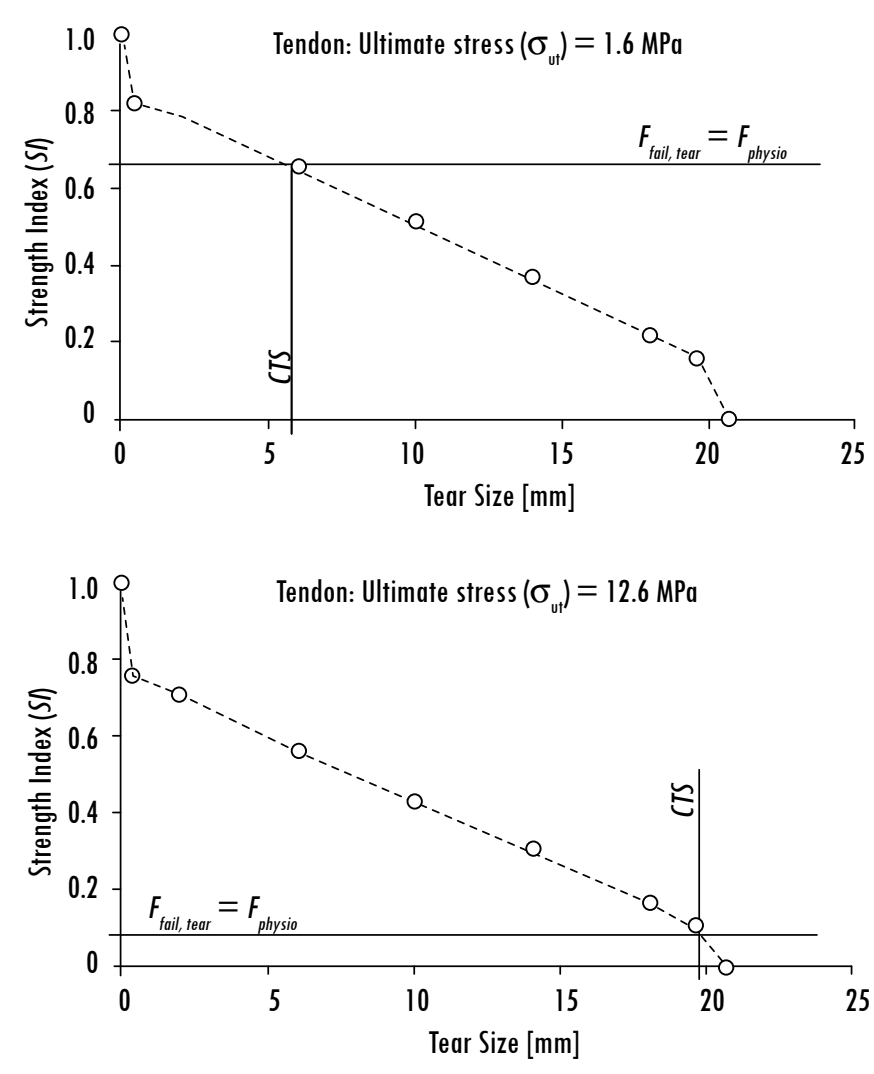

Source: authors' own presentation

This study provides quantification of the load-bearing capacity of the supraspinatus tendon through the definition of a Strength Index $(S I)$, ranging from 1 for healthy tendon to 0 for tendon with a full-width tear. In addition, this study provides a Critical Tear Size (CTS) at which the tendon cannot withstand maximal physiological force and there is a high risk of immediate and complete failure.

The implemented finite element model allowed for estimation of the failure force for the tested tendon based a range of ultimate stress values reported previously (Itoi et al., 1995; Sano et al., 1997). The wide range of the ultimate 
stress values is likely due to patient-dependent variables, such as fatty degeneration of the tendon. The failure force of a tendon with a tear decreased in a near linear fashion as the tear extended, as it has been reported previously with partial-thickness tears (Yang et al., 2009). This reduction on the failure force is larger for tendons with higher ultimate stresses, resulting in smaller variations in failure force as the tear size increases. This result indicates that the effects associated with patient variability are minor for larger tears.

Figure 8. Critical tear size as function of the ultimate stress for tested supraspinatus tendon

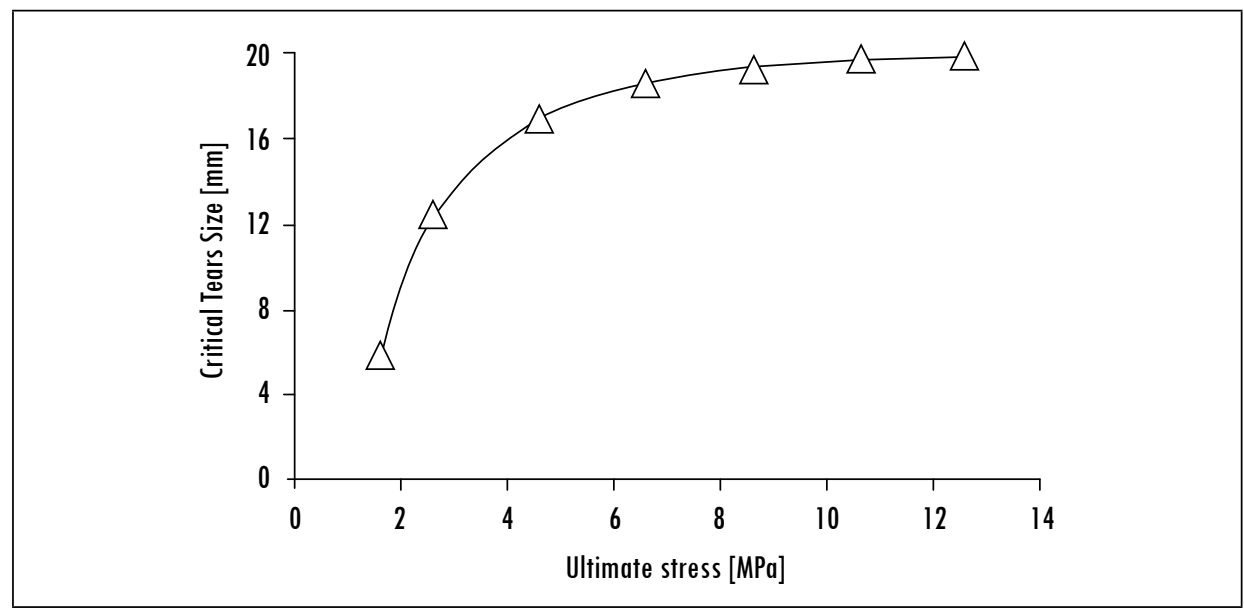

Source: authors' own presentation

The tested tendon was able to withstand the maximal physiological tensile force of the supraspinatus tendon (Hughes and An, 1996). In a tendon with a tear, the CTS decreased as the ultimate stress of the tissue decreased. The $S I$ was also dependent on the ultimate stress of the tissue and decreased with increasing tear size. For an ultimate stress of $12.6 \mathrm{MPa}$, the CTS was $19 \mathrm{~mm}$ and the $S I$ was estimated to be 0.1 , meaning that the failure force for a tear size of $19 \mathrm{~mm}$ was $10 \%$ of the ultimate force of the healthy tendon. In contrast, for an ultimate stress of $1.6 \mathrm{MPa}$, the CTS was approximately $6 \mathrm{~mm}$, and the $S I$ was equal to 0.65 . The variation in the $S I$ as a function of the ultimate stress of the tendon may be a limitation of the proposed method; however, it was essential for defining the CTS.

As expected, the CTS was defined as a function of the ultimate stress of the tendon. However, this relationship was non-linear. The tendon load bearing 
capacity was more vulnerable to a tear in the lower half of the physiological ultimate stress range $(1.6-7.1 \mathrm{MPa})$. Within this range, a tear of any size considerably reduced the load bearing capacity of the tendon and CTS. Tendons with an ultimate stress of $7.1 \mathrm{MPa}$ or higher were able to withstand tears of 18 $\mathrm{mm}$ or less with little risk of failure.

Clinically, the CTS has a potential as a useful parameter during diagnosis and surgery. A limitation of the presented method is that the ultimate stress of the tendon must be known to estimate the SI and CTS. One possible solution is to define failure of the tendon in terms of yield strain, as performed in a previous experimental study (Reilly et al., 2003a). In addition, in vivo estimation of tendon elastic modulus has been performed using ultrasound (Maganaris and Narici, 2005). The possible correlation between elastic modulus and ultimate strength is a potential area for future research and elastic modulus could be an additional alternate to ultimate stress in estimating SI and CTS. This study contributes to the understanding of tendon tearing and failure, but clinical application is likely limited by the accuracy of techniques employed for in vivo estimation of tendon mechanical properties.

The current study had additional limitations. The tendon was considered homogeneous, hyper-elastic and transversely isotropic, but this is still a simplification of the tissue's true mechanical behavior. Other simplifications include a $2 \mathrm{D}$ geometry and the application of only tensile loads. A tear that progresses as consequence of the applied load was not simulated. Instead, a number of tendon models exhibiting different tear sizes were implemented and solved individually.

Load bearing capacity of the supraspinatus tendon is highly affected by the ultimate stress of the tissue and tear size, as shown by the SI and CTS. The potential clinical use of the CTS is limited to the development of new techniques that allow for estimation of tendon ultimate stress. The load bearing capacity of the supraspinatus tendon may also be affected by uncertainties in the physiological load, the insertion geometry and local in-homogeneities, in addition to other factors that should be addressed in future studies.

\section{References}

ANDARAWIS-PURI, N.; RICCHETTI, E.T., and SOSLOWSKY, L.J. rotator cuff tendon strain correlates with tear propagation. Journal of Biomechanics. 2009, vol. 42, no. 2, p. 158.

BLAINE, T.A. and BIGLIANI, L.U. Rotator cuff disorders. In: Tendon injuries: Basic science and clinical medicine. Berlin: Springer-Verlag, 2005, pp. 119-127. 
BURKHART, S. The principle of margin convergence in rotator cuff repair as a means of strain reduction at the margin. Annals of Biomedical Engineering. 2004, vol. 32, no. 1, pp. 166-170.

CARR, A. and HARVIE, P. Rotator cuff tendinopathy. In: Tendon injuries: Basic science and clinical medicine. Berlin: Springer-Verlag, 2005, pp. 101-118.

CELEMIN, A. et al. A hyperelastic anisotropic model of the supraspinatus tendon. Journal of Biomechanics. 2012, vol. 45, p. S582.

DAVIDSON, J. and BURKHART, S.S. The geometric classification of rotator cuff tears: a system linking tear pattern to treatment and prognosis. Journal of Arthroscopic and Related Surgery. 2010, vol. 26, no. 3, pp. 417-424.

HOLZAPFEL, G.A. Nonlinear solid mechanics: A continuum approach for engineering. London: John Wiley \& Sons, 2000.

HUGHES, R.E. and AN, K.N. Force analysis of rotator cuff muscles. Clinical Orthopaedics and Related Research. 1996, vol. 330, no. 330, pp. 75-83.

INOUE, A. et al. Nonlinear stress analysis of the supraspinatus tendon using three-dimensional finite element analysis. Knee Surgery, Sports Traumatology, Arthroscopy. 2012, pp. 1-7.

ITOI, E. et al. Tensile properties of the supraspinatus tendon. Journal of Orthopaedic Research. 1995, vol. 13, pp. 578-584.

MAGANARIS, C.N. and NARICI, M.V. Mechanical properties of tendons. In: Tendon injuries: Basic science and clinical medicine. Berlin: Springer-Verlag, 2005, pp. 14-21.

NATALI, A.N. et al. A transversally isotropic elasto-damage constitutive model fot he perodontal ligament. Computer Methods in Biomechanics and Biomedical Engineering. 2003, vol. 6, no. 5-6, pp. 329-336.

NATALI, A.N. et al. Anisotropic elasto-damage constitutive model for the biomechanical analysis of tendons. Medical Engineering E Physics. 2005, vol. 27, no. 3, p. 209.

OGDEN, R.W. Non-linear elastic deformations. New York: Dover Publications, 1997.

REILLY, P. et al. Mechanical factors in the initiation and propagation of tears of the rotator cuff, quantification of strains of the supraspinatus tendon in vitro. The Journal of Bone and Joint Surgery. British Volume. 2003a, vol. 85, no. 4, pp. 594-599.

REILLY, P. et al. Supraspinatus tears: propagation and strain alteration. Journal of Shoulder and Elbow Surgery. 2003b, vol. 12, no. 2, pp. 134-138.

SALLAY, P.I.; HUNKER, P.J. and LIM, J.K. Frequency of various tear patterns in full-thickness tears of the rotator cuff. Journal of Arthroscopic and Related Surgery. 2007, vol. 23, no. 10, pp. 1052-1059.

SANO, H. et al. Degeneration at the insertion weakens the tensile strength of the supraspinatus tendon: A comparative mechanical and histologic study of the bone-tendon complex. Journal of Orthopaedic Research. 1997, vol. 15, no. 5, pp. 719-726. 
SANO, H.; WAKABAYASHI, I. and ITOI, E. Stress distribution in the supraspinatus tendon with partial-thickness tears: An analysis using two-dimensional finite element model. Journal of Shoulder and Elbow Surgery. 2006, vol. 15, pp. 100-105.

SANO, H. et al. Stress distribution in the supraspinatus tendon after tendon repair suture anchors versus transosseous suture fixation. The American Journal of Sports Medicine. 2007, vol. 35, no. 4, pp. 542-546.

SEKI, N. et al. Mechanical environment of the supraspinatus tendon: Three-dimensional finite element model analysis. Journal of Orthopaedic Science. 2008, vol. 13, no. 4, pp. 348-353.

TERRIER, A. et al. Effect of supraspinatus deficiency on humerus translation and glenohumeral contact force during abduction. Clinical Biomechanics. 2007, vol. 22, no. 6, pp. 645-651.

WAKABAYASHI, I. et al. Mechanical environment of the supraspinatus tendon: A twodimensional finite element model analysis. Journal of Shoulder and Elbow Surgery. 2003, vol. 12, pp. 612-617.

WEISS, J.A.; BRADLEY, N.M. and SANJAY, G. Finite element implementation of incompressible, transversely isotropic hyperelasticity. Computer Methods in Applied Mechanics and Engineering. 1996, vol. 135, no. 1-2, p. 107.

YANG, S. et al. biomechanical analysis of bursal-sided partial thickness rotator cuff tears. Journal of Shoulder and Elbow Surgery. 2009, vol. 18, no. 3, pp. 379-385.

YEOH, O.H. Some forms of the strain energy function for rubber. Rubber Chemistry and Technology. 1993, vol. 66, pp. 754-771. 
